\title{
Acid Rain and Environmental Problems: Implications for the Teaching of Biology in Schools in Riverine Communities
}

\author{
Osu, Samuel Robert \\ Ekpo, Mary Okon
}

\author{
Department of Biology, Akwa Ibom State College of Education, \\ Afaha Nsit, P.M.B. 1019, Etinan, Nigeria
}

\section{Doi:10.5901/ajis.2013.v2n12p101}

\begin{abstract}
This study was conducted to investigate the influence of acid rain and environmental problems on the teaching of Biology in schools in the riverine communities of Akwa Ibom State - Nigeria. One hundred and eighty (180) Biology teachers were selected using the stratified sampling technique. A questionnaire titled "Acid rain and Teaching of Senior Secondary Biology" (ARTSSB) was used to collect data for testing the four null hypotheses of the study at .05 level of significance. Data analysis was done using the t-test statistics. Findings were made that the damage of buildings by acid rain, the destruction of forest by acid rain, the devastation of arable land by acid rain and the acidification of surface and domestic waters by acid rain all had a significant influence on the study of senior secondary Biology. Recommendations were made among others that: the ecology component of the Biology curriculum for secondary schools should be effectively taught; important environmental issues including acidification of environment by acid rain should be incorporated into the senior secondary curriculum and be carefully thought by teachers of Biology.
\end{abstract}

Keywords: Acid rain, Environmental Problems, Teaching of Biology, and Riverine Communities.

\section{Introduction}

Acid rain is the term used in environmental science that represents mixing of environmental pollutants with the rain water (Wood, and Bormeann, 1994). The mixing raises the acidity of rain water by formation of acid following chemical reactions involving pollutant gases and water. In Nigeria, the traces of acid rain is noticed in the industrialized areas and its adverse effects damage our ecosystem (Johnston, Shiner, Waver and Lodge 1982).

Acid rain primarily affect the riverine communities of Akwa Ibom State - Nigeria. The major causes of acid rain in these communities is as a result of gas flaring. According to Nwaugo, Onyeagba and Nwahcukwu (2005) gas flaring is the control burning of natural gases associated with oil production. The consisted flaring has left a devastating effect on the surrounding environment, where the activities of the oil exploration and exploitation is greatest.

Orimoogunje et al., (2010) posited that flaring is still the most common practice to dispose the waste gases that are produced during conventional oil exploration in Nigeria. Oil Company like Exxon Mobil are involved in gas flaring in Nigeria. For Exxon Mobil to gain maximum economic profit, gas flaring is the most efficient way to dispose of the associated gas. The gases, after flaring can be carried hundreds of kilometers in the atmosphere and spread throughout the area where flaring is carried out. These gases are later converted to acid gas and deposited as rain. Wet deposition of acids occurs when any form of precipitation removes acids from the atmosphere and delivers it to the environment.

Jacobson (1991) suggested that, the impact of acid rain on environment is a global concern 
that needs to be handled by countries that are highly industrialized. However, the significance of this study is to address how acid rain affects our ecosystem and also suggest measures on how it can be remedied. For instance, the industrial pollutants introduced into the atmosphere by factory smokestacks, are spread over wide areas by the prevailing winds and fall to earth with precipitation called 'acid rain', lowering the $\mathrm{pH}$ of water on ground and killing life. Consequently, an attempt to capture and remove the pollutants instead of releasing them into the atmosphere seems very difficult to execute and costly. Therefore, the clean Air Act Revisions of 1990 addressed the problem in the United State significantly for the first time. In Nigeria, the effect of acid precipitation is seriously felt in the industrialized areas, where most companies dispose their wastes indiscriminately into the environment. On this note, the attention of the Federal Government of Nigeria is being drawn through our recommendations on how to tackle the menace of air pollutant in this area.

According to Wolosz (2001), acid rain has direct impacts on forest ecosystems and their inhabitants. The damage to the forest trees and plants is widespread. Acid rain damages leaves as it falls. Acid rain runoff from the trees and forest floor infiltrates the forest's water supplies; runoff that doesn't enter the water supply is absorbed by the soil. The consequence of this is just as it is for any soil or water source infected with acid rain. The plants and creatures die off, and the creatures that rely on those plants and smaller creatures lose their food source and die as well.

Charkrabbarty (1982) posited that those seeking expensive paint job on their car might want to think twice in areas directly affected by acid rain. The excess sulphur dioxide and nitrogen oxides in acid rain damages automobile paint and corrodes surfaces. It is believed that the acid rain causes the damage as it dries on, and evaporates from, the surface. Auto and paint coating manufacturers are trying to develop protective coatings that prevent acid rain corrosion.

Acid rain leaches out of the soil when it is absorbed by the arable land. This directly affects the minerals levels of the soil and the creatures, such as snails, that rely on that calcium for shell growth (Lee, Perrigan and Grothans 1981). Consequently, snails die off and birds, which eat them for calcium, lay eggs with shells that are weak and brittle and therefore fall to hatch. Decreased calcium also creates excess aluminium in the soil, preventing trees and other plant life from absorbing water. Weakened plant life cannot tolerate extreme temperature or fight off insects and disease (Wolosz, 2001). Acid rain directly affects the chemical and pH balances in surface and domestic waters. The ecological effect of acid rain are most clearly seen in the aquatic, or water, environments, such as streams, lakes and marshes. Acid rain runs off the land and ends up in streams, lakes and marshes. The rain also falls directly on these areas.

As the acidity of a lake increases, the water becomes clearer and the numbers of fish and other water animals decline. Some species of plant and animal are better able to survive in acidic water than others. Freshwater shrimps, snails, mussels are the most quickly affected by acidification followed by fish such as minnows, salmon and roach. Lee and Weber (1980) posited that, the role and fry (eggs and young) of the fish are the worst affected as the acidity of the water can prevent eggs from hatching properly, can cause deformity in young fish which also struggle to take in oxygen. The acidity of the water does not just affect species directly; it also causes toxic substances such as aluminium to be released into the water from the soil, harming fish and other aquatic animals.

Lakes, rivers and marshes each have their own fragile ecosystem with many different species of plants and animals all depending on each other to survive. If a species of fish disappears, the animals which feed on it will gradually disappear too. If the extinct fish used to feed on a particular species of large insect, that insect population will start to grow, this in turn will affect the smaller insects or plankton on which the larger insect feeds (Odewunmi, 1987).

This present study is therefore initiated in order to critically appraise the problems faced by the inhabitants of the riverine communities of Akwa Ibom State - Nigeria where acid rain pollution is predominant. 


\subsection{Statement of the Problem}

The problem that attracts the attention of the researcher is the obnoxious released of hydrocarbon pollutants into the environment as a result of gas flaring in the area where the research is currently carried out. The traces of acid rain were generally noticed, which include damages of the buildings, destruction of forest, devastation of arable land and acidification of surface and domestic waters which eventually lead to the destruction of aquatic life in the study area. According to Osu and Udo (2008), other consequences caused by acid rain that should be look into in this study in the environment include wearing away the waxy protective coating of leaves, damaging them and preventing them from being able to photosynthesize properly. A combination of these effects weakens the trees which means that they can be easily attacked by diseases and insects or injured by bad weather. It is not just trees that are affected by acid rain, other plants may also suffer. All these constitute the problems that must be addressed in this study.

\subsection{Purpose of the Study}

The purpose of this study is to assess implications that acid rain and environmental problems have on the study of senior secondary Biology in riverine communities of Akwa Ibom State - Nigeria. Specifically the study has the following:

i. To investigate the influence that the damage of buildings by acid rain has on the teaching of senior secondary Biology.

ii. To assess the influence that the destruction of forest by acid rain has on the teaching of senior secondary Biology.

iii. To ascertain the influence of devastation of arable land by acid rain on the teaching of senior secondary Biology.

iv. To assess the influence of acidification of surface and domestic water by acid rain on the study of senior secondary Biology.

\subsection{Significance of the Study}

This study is significant in the following ways:

i. The findings will be useful to Biology curriculum designers to include more environmental issues for the subject.

ii. Senior Secondary school students in the study area will benefit as they will be helped to learn useful skills for maintaining our devastated environment by acid rain.

iii. Teachers of Biology in Senior Secondary Schools in the study area will benefit from the findings as they will learn some methods for properly teaching the causes, effects and control measures for acid rain.

iv. The findings will benefit the entire schools in the inhabitants of the riverine communities in Akwa Ibom State - Nigeria as they may have good knowledge of the adverse effect of acid rain on water bodies.

\subsection{Research Questions}

i. In what way does the damaging of buildings by acid rain influence the teaching of Biology in secondary schools in riverine communities of Akwa I bom State - Nigeria?

ii. How does the destruction of forest by acid rain influence the teaching of Biology in secondary schools in the riverine communities of Akwa Ibom State - Nigeria?

iii. To what extent does the devastation of arable land by acid rain influence the teaching of Biology in secondary schools in riverine communities of Akwa Ibom State - Nigeria?

iv. (How does the acidification of surface and domestic waters by acid rain influence the 
teaching of Biology in secondary schools in the riverine communities of Akwa Ibom State Nigeria?

\subsection{Research Hypothesis}

The following null hypotheses were formulated and tested to guide the study:

i. The damage of buildings by acid rain does not have any significant influence on the teaching of Biology.

ii. The destruction of forest by acid rain does not have any significant influence on the teaching of Biology.

iii. The devastation of arable land by acid rain does not have any significant influence on the teaching of Biology.

iv. The acidification of surface and domestic waters by acid rain has no significant influence on the teaching of Biology.

\section{Methodology}

\subsection{Research Design}

This study is survey research of the opinion of randomly selected teachers of Biology in schools in the riverine communities of Akwa Ibom State - Nigeria. The survey design is used when one is assessing the opinion, attitude of or occurrence of events in an area.

This study was conducted in schools in the riverine communities of Akwa Ibom State Nigeria. It is made up of Eket, Ibeno, Eastern Obolo, Onna, Esit Eket and Ikot Abasi Local Government Areas.

\subsection{Population of the Study}

The population of the study comprised all teachers of Biology in Senior Secondary Schools in the riverine communities of Akwa Ibom State - Nigeria.

\subsection{Sample and Sampling Technique}

The stratified random sampling technique was used to select 30 Biology teachers from secondary schools in each of the Local Government Areas in the riverine communities. This gave a sample size of 180 teachers.

\subsection{Research Instrument}

A questionnaire titled "Acid Rain and the Teaching of Biology Questionnaire" (ARTBQ) was used to collect data for the study. The questionnaire was structure using a 4 - point scale to reflect the hypotheses of the study.

The questionnaire was validated by the expert opinion of lecturers of Measurement and Evaluation and Research Methods in the University of Uyo. They went through the items to ensure that only relevant ones were included.

The test - retest method was used to ascertain the reliability of the questionnaire. It was administered first to a group of 30 Biology teachers in Nsit-Ibom and Nsit-Ubium L.G.A. who obviously were not part of the main study. After one week there was a second administration to the same group and the two scores correlated by computing Pearson Product Moment Correlation. A coefficient of .68 was obtained. This showed that the questionnaire was reliable and could be used for the study. 
The researcher with two research assistants visited the schools selected for the study and after due consultation with the principals distributed the copies of the questionnaire to the selected teachers. The respondents were given enough time to enable them complete the questionnaire. The copies of the questionnaire were collected back on the same day to avoid loss.

\subsection{Method of Data Analysis}

The data collected for the study were analysed by calculating the related t-test. The results were used to test the four null hypotheses at .05 level of significance.

\section{Results}

Hypothesis 1: The damage of Buildings by acid rain does not have any significant influence on the teaching of Biology in secondary schools in riverine communities of Akwa Ibom State - Nigeria.

Table 1: t-test Analysis of the Influence of damage of Buildings by Acid Rain on the teaching of Senior Secondary Biology

\begin{tabular}{|c|c|c|c|c|c|c|c|}
\hline Variables & $\mathbf{N}$ & $(\overline{\mathbf{x}})$ & $\mathbf{r}$ & t-cal. & t -crit. & Df & Decision \\
\hline Damage of Buildings by Acid Rain & 180 & 4.68 & \multirow{2}{*}{.63} & 10.62 & \multirow{2}{*}{1.96} & \multirow{2}{*}{178} & Rejected \\
\hline Teaching of senior secondary Biology & 180 & 4.08 & & & &
\end{tabular}
$P>0.05$

The result in Table 1 showed that the calculated t-value of 10.62 was greater than the critical tvalue of 1.96 , with this result the first null hypothesis was rejected at .05 level of significance.

Hypothesis 2: The destruction of forest by acid rain does not have any significant influence on the teaching of Biology in secondary schools in riverine communities of Akwa Ibom State - Nigeria.

Table 2: t-test Analysis of the Influence of Destruction of forest by Acid Rain on the teaching of Senior Secondary Biology

\begin{tabular}{|c|c|c|c|c|c|c|c|}
\hline Variables & $\mathbf{N}$ & $(\overline{\mathbf{x}})$ & $\mathbf{R}$ & t-cal. & t -crit. & Df & Decision \\
\hline Destruction of forest by Acid Rain & 180 & 4.71 & \multirow{2}{*}{62} & 10.60 & \multirow{2}{*}{1.96} & \multirow{2}{*}{178} & Rejected \\
\hline Teaching of senior secondary Biology & 180 & 4.08 & & &
\end{tabular}

$P>0.05$

The result in Table 2 showed that the calculated t-value of 10.60 was greater than the critical tvalue of 1.96, with this result the second null hypothesis was rejected at .05 level of significance.

Hypothesis 3: The devastation of arable land by acid rain does not have any significant influence on the teaching of Biology in secondary schools in riverine communities of Akwa Ibom State - Nigeria.

Table 3: t-test Analysis of the Influence of Devastation of Arable land by Acid Rain on the teaching of Senior Secondary Biology

\begin{tabular}{|l|c|c|c|c|c|c|c|}
\hline \multicolumn{1}{|c|}{ Variables } & $\mathbf{N}$ & $(\overline{\mathbf{x}})$ & $\mathbf{r}$ & t-cal. & t -crit. & Df & Decision \\
\cline { 1 - 7 } Devastation of Arable land by Acid Rain & 180 & 4.29 & \multirow{2}{*}{.73} & 14.32 & \multirow{2}{*}{1.96} & \multirow{2}{*}{178} & Rejected \\
\hline Teaching of senior secondary Biology & 180 & 4.08 & & &
\end{tabular}

$P>0.05$

The result in table 3 showed that the calculated t-value of 14.32 was greater than the critical t- 
value of 1.96. Thus the third null hypothesis was rejected at .05 level of significance.

Hypothesis 4: The acidification of surface and domestic waters by acid rain does not have any significant influence on the teaching of Biology in secondary schools in riverine communities of Akwa Ibom State - Nigeria.

Table 4: t-test Analysis of the Influence of acidification of surface and domestic waters by Acid Rain on the teaching of Senior Secondary Biology.

\begin{tabular}{|l|c|c|c|c|c|c|c|}
\hline \multicolumn{1}{|c|}{ Variables } & N & $(\overline{\mathbf{x}})$ & r & t-cal. & t -crit. & Df & Decision \\
\cline { 1 - 8 } $\begin{array}{l}\text { Acidification of surface and domestic waters } \\
\text { by Acid Rain }\end{array}$ & 180 & 4.17 & 0.66 & 11.75 & 1.96 & 178 & Rejected \\
\cline { 1 - 6 } Teaching of senior secondary Biology & 180 & 4.08 & & & & \\
\hline
\end{tabular}

$P>0.05$

The result in Table 4 showed that the calculated t-value of 11.75 was greater than the critical tvalue of 1.96. The fourth null hypothesis was thus rejected at .05 level of significance.

\subsection{Discussion of Findings}

The first finding of the study was that the damage of buildings of acid rain has a significant influence on the teaching of Biology in secondary schools in the riverine community of Akwa Ibom State - Nigeria. This means that the occurrence of acid rain in the area causes the damage of buildings, thus the excess sulphur dioxide and nitrogen oxides in acid rain damaged expensive paints on buildings and even corrodes surfaces of galvanized zincs used for roofing buildings (Wolosz, 2001). These make the teachers of Biology in secondary schools in the study area to teach students a lot about the impact of acid rain on environment such as corrosive effect in monuments made on sensitive materials like limestone etc.

The second finding of the study was that the destruction of forest by acid rain has a significant influence on the teaching of Biology in secondary schools in the study area. This means that acid rain cause threat to forests. The pollutants gets deposited on the surface of the plants and interfere with photosynthesis. This abruptly cause death of plants. Acid deposition due to rainfall has potential to affect sensitive forest (Irving and Miller, 1980). Since education is given to provide man with the skills, attitude and knowledge to understand his environment and solve problems therein. The teachers of Biology would teach the students to understand that acid rain directly impact forest ecosystem and their inhabitants. Further more, acid rain has been shown to decrease the growth of forest trees in Sweden (Noggle, 1980).

The third finding was that devastation of arable land by acid rain has a significant influence on the teaching of Biology in secondary schools in the riverine community of Akwa Ibom State Nigeria. This means that acid rain leaches calcium out of the soil when it is absorbed by the arable land. This directly affects the mineral levels of the soil and plant growth and soil productivity will be completely slowed down (Gelmon, 1998). Further more, the nutrients and minerals in the soil which help the trees to grow such as potassium, calcium and magnesium. All this facts will exposed the teachers of Biology in the study area to communicate this knowledge to the students they thought (Ferenbough, 1976).

The fourth finding of this study was that the acidification of surface and surface and domestic waters has significant influence on the teaching of Biology in secondary schools in the study area. This means that the effects of acid rain on aquatic habitats are most obvious. Johnston, et al., (1982) suggested that acid rain directly affects the chemical and pH balance of surface and domestic waters. Furthermore, the excess aluminiums created by acid rain makes aquatic environment such as lakes and streams toxic which can cause damage to fish and other aquatic animals. With this finding, the teachers of Biology can now expose the students to most of these 
consequences of acid rain on the environment.

\section{Summary}

This study was conducted to investigate the influence of acid rain and environmental problems on the teaching of Biology in schools in the riverine communities of Akwa Ibom State - Nigeria. One hundred and eighty (180) Biology teachers were selected using the stratified sampling technique. A questionnaire titled "Acid rain and Teaching of Senior Secondary Biology" (ARTSSB) was used to collect data for testing the four null hypotheses of the study at .05 level of significance. Data analysis was done using the t-test statistics. Findings were made that the damage of buildings by acid rain, the destruction of forest by acid rain, the devastation of arable land by acid rain and the acidification of surface and domestic waters by acid rain all had a significant influence on the teaching of Biology in schools in the riverine communities of Akwa Ibom State - Nigeria.

\section{Implications for the Teaching of Biology in Schools}

One of the science subjects in the senior secondary school curriculum is Biology. Almost all students offer it as a necessary science subject. The findings of this study have the following implications for the teaching of the subject.

1. The aspect of the subject known as Ecology has been avoided by many teachers and students in the past. This study has shown that acid rain destroys both terrestrial and aquatic habitats. This aspect has to be properly taught now so as to make students aware of the danger of acid rain to their immediate environment.

2. Field trips have to be organized once in a while to the riverine communities where oil drilling activities are carried out by oil companies. This will enable students and teachers to have first hand knowledge about the devastation that acid rain makes on the environment.

3. Environmental education at the secondary school is provided through many carrier subjects such as Biology. Qualified and environmental friendly teachers when employed can teach this aspect well to students.

\section{Recommendations}

From the findings, the following recommendations are made.

i. Existing environmental laws in Nigeria should be enforced by the Federal Government.

ii. Field trips and discussion methods should be used as part of the strategies for teaching Biology in schools in the riverine communities where acid rain is noticed.

iii. Increased public awareness should be created on causes, effects and control of acid rain in the riverine communities of Akwa Ibom State - Nigeria.

iv. The component of Ecology in senior secondary Biology curriculum should be carefully taught by teachers of the subject.

v. Several environmental issues including acidification of environment by acid rain should be incorporated into the senior secondary curriculum and be carefully thought by teachers of Biology.

\section{Conclusion}

The problem of acid rain in the riverine communities of Akwa Ibom State - Nigeria has been an issue of great concern not only to the inhabitants of the area but also to all environment sensitive people. This has led a wide scale destruction of the environment as well as the flora and fauna (Liken et al. 1979). 
It was revealed in the study that acid rain has a significant influence on the teaching of Biology in schools in the riverine communities of Akwa Ibom State - Nigeria. This influence is based on the effects of acid rain on building, forest, arable land and acidification of surface and domestic waters. The following conclusions were therefore made that:

i. Acid rain has an adverse effect on the life of the people in the riverine communities of Akwa I bom State - Nigeria.

ii. That acid rain can be control through effective teaching of ecological component of Biology in schools in the study area.

iii. That teaching methods such as field trips and discussion could help students to gain more knowledge about the influence of acid rain pollution and environmental problems in the riverine communities of Akwa Ibom State - Nigeria.

\section{References}

Charkrabbarty, A. M. (1982). Biodegradation and Detoxification of Environmental Pollutants. C. R. S Press, Florida, Pp. 103 - 105.

Ferenbough, R. W. (1976). Effect Simulated Acid Rain on Phasecoh Velgaris (fabacea American). Journal of Botany $63: 283-288$.

Gelmon, H. (1998). Problems in Crop Seed germination: crop physiology edited by S. Guptel: Oxford and I. B. H. Publishing Company New Delhi, Pp. 1 - 78.

Irving, P. M. and Miller, J. E. (1980). Response of Field Grown Soybeans to Acid Precipitation alone and in Combination with Sulfur Dioxide. Drables and Tollan eds. Processing International Conference on Ecological Effect of Acid Rain Precipitation, Sandford, Norway. Pp. 170 - 171.

Jacobson, J. S. (1991). The Effect of Acid Precipitation on Crops: Acid Deposition in Europe ed. M. J. Chadwick and M. Hutton: Stockholm Environment Institute, New York Pp. 81 - 98.

Johnston, J. W; Shiner, D. S; Waver, O. T. and Lodge, D. M. (1982). Effect of Rain pH on Senescence, Growth and Yield of Bush Beans: Environmental Experiment Botany 22. Pp. 329.

Lee, J. J. and Weber, D. E. (1980). The Effect of Simulated Acid Rain on the Seedling. Emergence and Growth of Eleven Wood Species: Forestry Science 25. Pp. 395 - 398.

Lee, J. J; Neely, G. E; Perrigan, S. S. C. and Grothans, L. C. (1981). Effect of Simulated Acid Rain on Yield, Growth and Foliar I njury of Several Crops: Environmental Experiment 21. Pp. 171 - 185.

Likens, G. E; Wright, R. F. Galloway, J. N. and Butter, J. J. (1979). Acid Rain: Science American. 25. 241 (14) : $43-53$.

Noggle, J. C. (1980). Sulphur Accumulation by Plants, the Role of Gaseous Sulphur in Crop Nutrition. Edited by D. S. Shier Ann Arbo Science Publishers. Pp. 289 - 297.

Nwaugo, V. O., Onyeabga, R. A. and Nwahcukwu, N. C. (2005). Effect of Gas Flaring on Soil Microbial Spectrum in Parts of Niger Delta Area of Southern Nigeria. African Journal of Biotechnology. Vol. 5 (19) : Pp. $1824-1826$.

Odewunmi, A. (1987). Pollution in Nigeria. A Report on Environmental Pollution Shell Pet. Dev. Co. Warri (in House report).

Orimoogunje, O. O. I., Ayanlade, T. A., Akinkuolic and Odiong, A. U. (2010). Perception on Effect of Gas Flaring on the Environment. Research Journal of Environmental and Earth Science 2 (4) : 188 193.

Osu, S. R. and Udo, B. A. (2008). Adverse Effect of Acid Rain Pollution on Environment. National Journal of Science and Technology. A Publication of School of Science, College of Education, Afaha Nsit Akwa Ibom State - Nigeria. (3) : 123 - 130.

Wolosz, T. (2001). The Effect of Acid Rain on the Environment. National Geographic Reports on the Causes of Acid Rain. Water Policy International Ltd. 1 Dome Hill, Caterham, Surrey CR3 6EE, UK.

Wood, T. and Bormeann, F. H. (1994). The Effect of Artificial Mist upon the Growth of B. Allegheninsis: Birth Environmental Pollution 1. Pp. 259 - 268. 